\title{
Treatment of Recurrent Aphthous Stomatitis by 100\% Topical Pumpkin Seed Oil
}

\author{
Khalifa E. Sharquie ${ }^{1}$, Adil A. Noaimi' ${ }^{1}$, Tuqa M. Latif ${ }^{2}$ \\ ${ }^{1}$ Department of Dermatology, College of Medicine, University of Baghdad, Iraqi and Arab Board for Dermatology and \\ Venereology, Baghdad Teaching Hospital, Medical City, Baghdad, Iraq \\ ${ }^{2}$ Department of Dermatology, Baghdad Teaching Hospital, Medical City, Baghdad, Iraq \\ Email: *ksharquie@ymail.com, adilnoaimi@yahoo.com, tuqa.mohammed9@yahoo.com
}

How to cite this paper: Sharquie, K.E., Noaimi, A.A. and Latif, T.M. (2017) Treatment of Recurrent Aphthous Stomatitis by 100\% Topical Pumpkin Seed Oil. Journal of Cosmetics, Dermatological Sciences and Applications, 7, 324-335.

https://doi.org/10.4236/jcdsa.2017.74029

Received: June 3, 2017

Accepted: December 12, 2017

Published: December 15, 2017

Copyright ( $) 2017$ by authors and Scientific Research Publishing Inc. This work is licensed under the Creative Commons Attribution International License (CC BY 4.0).

http://creativecommons.org/licenses/by/4.0/

(c) (i) Open Access

\section{Abstract}

Background: Recurrent aphthous stomatitis (RAS) is a major oral health problem, where its etiopathogenesis is not well understood. Accordingly, its therapy whether topical or systemic can induce clearance, but the relapse rate is high. Objective: To use $100 \%$ topical pumpkin seed oil in RAS as it has many actions as anti-inflammatory and antioxidant effects. Patients and Methods: This single, blind, clinical, therapeutic trial was conducted in the Department of Dermatology-Baghdad Teaching Hospital, Baghdad, Iraq, during February 2015-August 2016. Twenty-five patients with RAS were included in this work. After full history and clinical examination, the clinical diagnosis was established. Oral clinical manifestation index score (OCMI) was carried out before, during and after stopping therapy to assess the different parameters of this score. $100 \%$ Topical pumpkin seed oil was given two times daily for 3 months during which short term assessment for each patient was done by using OCMI before, after 4 days and after 8 days of therapy in addition to assessing the mean size of largest diameter of ulcers in each visit to evaluate the therapeutic efficacy of the therapy, while long term assessment of the OCMI was done every month for 3 months after starting of the therapy to evaluate the prophylactic effect of the therapy. After 3 months, pumpkin seed oil was stopped and assessment of OCMI was done monthly for another 3 months to evaluate the remission action of pumpkin seed oil. Results: Twenty-five patients were included in this study: 15 (60\%) males and 10 (40\%) females. While their ages ranged from $9-60(27.48 \pm 11.97)$ years. The mean of OCMI before pumpkin seed oil therapy was ranged from $9-15$ (12.96 \pm 1.42$)$, while after the therapy the mean started to decline to lower level within 4 days of therapy and was statistically significant $(\mathrm{p}<0.0001)$ and continued to decline significantly till the end of third month of therapy $(\mathrm{p}<0.0001)$. The percent reduction was $79.30 \%$ after 4 days of therapy and $94.38 \%$ after 8 days 
of therapy. After stopping therapy, the mean of OCMI started to increase, but it is remained statistically highly significant $(p<0.0001)$ at the end of third months after stopping therapy when it is compared with baseline mean of OCMI. Conclusion: Pumpkin seed oil had an effective therapeutic and prophylactic action against RAS, in addition, it induced remission for at least 3 months after stopping therapy. No local or systemic side effects were observed during the course of therapy.

\section{Keywords}

Recurrent Aphthous Stomatitis, Pumpkin Seed Oil, Therapy

\section{Introduction}

Recurrent aphthous stomatitis (RAS) is one of most common cause of oral ulceration that associated with a major health problem as its effect at least $20 \%$ of population all over the world [1]. There are many varieties of RAS like minor, major and herpetiform. Minor ulcers (80\%) are less than one centimeter in diameter, usually heal within 2 weeks without scarring. Major ulcers (10\%) usually one centimeter or more in diameter, take 10 - 40 days to heal and may leave scars, while herpetiform ulcers (10\%) are cluster of dozens of smaller ulcers [2].

There are many theories have been suggested to explain its etiopathogenesis but the proper cause is still not fully explained [3]. These theories include: Genetic predisposition [4] [5] [6]; Immunological abnormalities [7]-[13]; Hematological abnormalities [14] [15] Infectious causes [16] [17] [18]; Hormonal factors [19] [20]; Smoking [21] [22] [23]; Trauma [1]; Stress [24]; and Food allergies [19].

There are many therapeutic agents that have been used in treatment of RAS aiming to reduce the frequency of ulceration and to minimize the discomfort that associated with disease activity but the doctors and patients aims are to have full recovery and even cure, these agents include: chlorhexidine [4]; topical honey [25]; 5\% lactic acid mouth wash [26]; Nigella sativa oil [27]; tetracyclin and their derivative (doxycycline and minocycline) [28]; BCG vaccine [29]; oral dapson and zinc sulfate [30]; oral steroid [31]-[34]; oral colchicine [35]; and oral clofazimine [31]. Recently, an Iraq study showed that oral isotretinoin had an effective therapeutic and prophylactic role in management of RAS [36].

Pumpkin has been reported in Holy Quran in story of the prophet of the God (Younis).

(In the name of Allah, most Gracious, most Merciful).

(But we cast him forth on the naked shore in state of sickness (145) and we caused to grow, over him, a spreading plant of gourd kind (146). AL-SAFFAT). (Holy Quran).

Pumpkin seed oils are good source of vitamins, minerals and anti-oxidants [37]. Active components include fatty acid, 19.4\% saturated fatty acids (palmitic 
acid and stearic acid), $80.7 \%$ unsaturated fatty acids (linoleic acid and oleic acid) [38], Tocopherol ( $\beta$-tocopherol, $\gamma$-tocopherol, $\delta$-tocopherol), carotenoids including $\beta$-carotene and lutein [39], Phytosterols or plant sterols [40], Amino acid Glutamic and aspartic acid, leucine, valine, phenylalanine, and tryptophan are among the amino acids identified [41]. It has many therapeutic activities like antioxidant activity [42] [43] [44], anti inflammatory [45], antimicrobial activity [46] [47], and anti carcinogenic effect [48].

Accordingly, the aim of present work is to use pumpkin seed oil as topical therapy for RAS aiming to find a new safe, effective treatment that could be much more helpful and cost effective than other therapies.

\section{Patients and Methods}

This is a single, blind, clinical, therapeutic trial to evaluate the effectiveness of $100 \%$ topical pumpkin seed oil in treatment and prophylaxis of recurrent aphthous stomatitis (RAS). Twenty-five Patients with RAS included in this study were those who attended Baghdad Teaching Hospital-Department of Dermatology in the period from February 2015 to August 2016.

Inclusion criteria: patients with RAS in the present work were those with early onset ulceration (less than 3 days duration) and had little or no benefit obtained from other conventional therapy in previous attacks and stopped their treatment at least two months before. Patients were requested to avoid the use of any medicaments throughout the trial.

The diagnosis of RAS was based on history and clinical examination. History was obtained regarding age, gender, occupation, history of disease, the recurrence rate, their general health and previous medical history and history of the same condition or other illness in the family. Also, they were asked about any aggravating factors including food, stress, trauma and smoking or associated symptoms. All patients were fully examined regarding shape, size and number of the lesions.

Investigations were done for all patients regarding: pathergy test, complete blood picture, ESR and HLA typing for HLA-B5, 51 and HLA-B27 to exclude patients with Behcet's disease and other internal causes of oral ulcerations. All patients were seen by ophthalmologists, Neurologist and Rheumatologist to exclude findings suggestive for Behcet's disease.

\subsection{Drug Preparation}

Pumpkin seed oil 100\% was ready made in Iraq-Mousl, EMAD trade mark kept in a clean and tight container till usage.

Patients instructed to use pumpkin seed oil topically two times daily for 3 months. All patients instructed not take any other drug for their aphthous ulcer during the course of the study, and to return if they developed drug side effects. An oral clinical manifestations index (OCMI) [26] (Table 1), for each patient was calculated before, during and after therapy to assess the response to treatment. 
Table 1. Oral clinical manifestation index.

\begin{tabular}{|c|c|}
\hline Type & Scoring \\
\hline Minor ulcer & 1 \\
\hline Herpetiform ulcer & 2 \\
\hline Major ulcer & 3 \\
\hline \multicolumn{2}{|l|}{ Number of ulcers/attack } \\
\hline $1-3$ & 1 \\
\hline $4-6$ & 2 \\
\hline $7-9$ & 3 \\
\hline $9-12$ & 4 \\
\hline More than 12 & 5 \\
\hline \multicolumn{2}{|l|}{ Duration of the attack } \\
\hline 1 - 4 days & 1 \\
\hline 5 - 8 days & 2 \\
\hline 9 - 12 days & 3 \\
\hline More than 12 days & 4 \\
\hline \multicolumn{2}{|l|}{ Frequency (attack/date) } \\
\hline 0 - 2 weeks & 5 \\
\hline 3 - 4 weeks & 4 \\
\hline 5 - 6 weeks & 3 \\
\hline 7 - 8 weeks & 2 \\
\hline More than 8 weeks & 1 \\
\hline \multicolumn{2}{|l|}{ Associated symptoms } \\
\hline Uncomfortable & 1 \\
\hline Painful, but not interfere with eating or swallowing & 2 \\
\hline Interfere with solid feeding & 3 \\
\hline Interfere with liquid feeding & 4 \\
\hline
\end{tabular}

\subsection{Follow-Up}

* Short term assessment (The therapeutic effect of drugs):

An assessment was performed for each patient on day 4 and 8 from starting therapy using OCMI with exclusion of the score of frequency of attacks since we are trying to evaluate the therapeutic efficacy. Also, the size of each oral ulcer was recorded before starting therapy and on day 4 and 8 after starting therapy, then mean size of ulcers was calculated for each patient on each visit. The size of ulcer was estimated depending on the largest diameter of the ulcer.

\section{* Long term assessment.}

The OCMI score was recalculated for each patient monthly for 3 months after starting the therapy to evaluate the prophylactic efficacy of $100 \%$ pumpkin seed oil and monthly for 3 months after stopping the drug to evaluate the remission 
efficacy of $100 \%$ pumpkin seed oil.

\subsection{Statistical Analysis}

The data were analyzed, and ANOVA test was used to compare the means of OCMI before, after 4 days and after 8 days of therapy.

The response rate was estimated by calculating the percentage of change in the means of OCMI after 4 and 8 days of therapy from the baseline of mean of OCMI before therapy.

Also, ANOVA test was used to compare the means of OCMI before, after 1 month, 2 months and 3 months of therapy and to compare the means of OCMI before therapy, 1 month, 2 months and 3 months after stopping the therapy. P-value of less than 0.05 was considered to be statistically significant.

\section{Results}

\subsection{Gender and Age}

Twenty-five patients were included in this study: 15 (60\%) males and $10(40 \%)$ females. Their ages ranged between $9-60$ years with a mean \pm SD of $27.48 \pm$ 11.97 years. Family history was positive in 12 (48\%) of patients.

Age distribution was clarified in the Table 2 which revealed that higher frequency of patients with RAS involved in this trial in the third and fourth decades of life.

Regarding type of ulcer 20 patients $(80 \%)$ had minor type and 5 patients (20\%) had major type.

\subsection{The Therapeutic Effect of Drug}

\subsubsection{The Effect of Drug on OCMI Score}

The OCMI before therapy ranged between 9 - 15 with a mean \pm SD of $12.96 \pm$ 1.42 , and the mean started to decline significantly to a lower level after 4 days of therapy to be $2.76 \pm 1.50$, $\mathrm{P}$ value $<0.0001$. While after 8 days of therapy a significant lower level of data was recorded, and the mean was $0.72 \pm 1.48$, which was statistically significant $\mathrm{P}$ value $<0.0001$ (Table 3 ).

The percent reduction for mean of OCMI after 4 and 8 days of therapy from the baseline of mean before therapy, was $79.30 \% \pm 10.80 \%$ after 4 days of therapy and $94.38 \% \pm 11.95 \%$ after 8 days of therapy.

Table 2. The distribution of age.

\begin{tabular}{ccc}
\hline Age (yrs.) & NO. & $\%$ \\
\hline$<20$ & 5 & 20 \\
$20-29$ & 9 & 36 \\
$30-39$ & 7 & 28 \\
$40-49$ & 3 & 12 \\
$>50$ & 1 & 4 \\
Total & 25 & 100 \\
\hline
\end{tabular}




\subsubsection{The Effect of Drug on Mean Size of Ulcers}

The mean size of ulcers before therapy ranged between $3-10 \mathrm{~mm}$ with a mean \pm SD of $6.20 \pm 2.67$, and the mean started to decline significantly to a lower level within 4 days of therapy to be $0.72 \pm 1.33$. P value $<0.0001$, and continued to decline till the $8^{\text {th }}$ day of therapy to be $0.04 \pm 0.20$, which was statistically significant $\mathrm{P}$ value $<0.0001$ when compare with $4^{\text {th }}$ day (Table 4 ).

While percent reduction for mean of size was $88.90 \% \pm 24.89 \%$ after 4 day of therapy and $99.56 \% \pm 2.18 \%$ after 8 days of therapy.

\subsubsection{The Prophylactic Effect of Pumpkin Seed Oil during Three Months Therapy}

Before therapy, OCMI was ranged between 9- 15 with mean \pm SD of $12.96 \pm$ 1.42. after pumpkin seed oil has been given, the mean of OCMI started to decline to be $1.24 \pm 3.44$ at the end of first month of therapy which was statistically significant $(\mathrm{P}$ value $<0.0001$ ), then it continued to decrease to be $1.12 \pm 3.11$ at the end of second month and $0.84 \pm 2.32$ at the end of third month of therapy which were statistically significant $(P$ value $<0.0001)$ (Table 5).

Table 3. The effect of pumpkin seed oil on OCMI of the ulcers.

\begin{tabular}{cccc}
\hline \multirow{2}{*}{ Pumpkin seed oil 100\% } & \multicolumn{2}{c}{ OCMI } & SD \\
\cline { 2 - 4 } & Range & Mean & 1.42 \\
At day 0 & $9-15$ & 12.96 & 1.50 \\
At day 4 & $2-7$ & 2.76 & 1.48 \\
At day 8 & $0-6$ & 0.72 & \\
& \multicolumn{2}{c}{ P value $<0.0001$} \\
\hline
\end{tabular}

Table 4. The effect of pumpkin seed oil on size of ulcers.

\begin{tabular}{cccc}
\hline Mean size of ulcers & Range & Mean & SD \\
\hline At day 0 & $3-10 \mathrm{~mm}$ & 6.20 & 2.67 \\
At day 4 & $0-4 \mathrm{~mm}$ & 0.72 & 1.33 \\
At day 8 & $0-1 \mathrm{~mm}$ & 0.04 & 0.20 \\
& P value $<0.0001$ & \\
\hline
\end{tabular}

Table 5. The prophylactic effect of pumpkin seed oil on OCMI score during course of therapy.

\begin{tabular}{cccc}
\hline OCMI score & Range & Mean & SD \\
\hline At day 0 & $9-15$ & 12.96 & 1.42 \\
At month 1 & $0-11$ & 1.24 & 3.44 \\
At month 2 & $0-10$ & 1.12 & 3.11 \\
At month 3 & $0-7 \quad 0.84$ & 2.32 \\
\hline
\end{tabular}




\subsubsection{The Remission Effect of Pumpkin Seed Oil during Three Months after Stopping Therapy}

After stopping therapy, OCMI started to increase slightly to be $0.96 \pm 3.33$ at the end of first month after stopping therapy, but remained statistically significant ( $\mathrm{P}$ value $<0.0001$ ), then it continued to increase to be $3.80 \pm 4.80$ at the end of second month after stopping therapy which was statistically significant ( $\mathrm{P}$ value $<$ $0.0001)$, then it decrease to reach $3.16 \pm 4.43$ at the end of third month after stopping therapy ( $\mathrm{P}$ value $<0.0001$ ) (Table 6).

\subsubsection{Side Effects}

No side effects were noticed in all patients.

\section{Discussion}

Recurrent aphthous stomatitis (RAS) is one of the most common painful oral mucosal disease that probably afflicts at least $20 \%$ of population, present first in childhood or adolescence [1]. Multifactorial etiopathogenesis has been suggested to explain the cause of RAS but the exact etiology and pathogenesis still not well elucidated [3].

Despite numerous clinical trials, no medication gives completely reliable cure, Still some patients might get remission either as a result of therapy or spontaneously [30].

A large number of therapies both topical and systemic have been used in treatment of RAS, including tetracycline [28], topical honey [25], Lactic acid 5\% mouthwash [26], BCG vaccine [29], Nigella sativa oil [27], dapsone and zinc sulfate [30], oral colchicine [30], oral isotretinoin [36], and oral clofazmine [31]. These therapies act through different mechanisms with variable success rate and most of them were associated with a variety of side effects.

Pumpkin seed oil are good source of vitamins, minerals and anti-oxidants [37], it has many therapeutic activities like antioxidant activity [42] [44], anti inflammatory [45], antimicrobial activity [46] [47], and anti carcinogenic effect [48].

The present study using topical pumpkin seed oil $100 \%$ showed a significant therapeutic and prophylactic effect in controlling RAS. The effect of this drug on OCMI was statistically significant after 4 days of therapy $(P$ value $<0.0001)$ and

Table 6. The remission effect of pumpkin seed oil on mean of OCMI during three months after stopping therapy.

\begin{tabular}{cccc}
\hline OCMI score & Range & mean & SD \\
\hline At day 0 & $9-15$ & 12.96 & 1.42 \\
After 1month & $0-13$ & 0.96 & 3.33 \\
After 2 months & $0-12$ & 3.80 & 4.80 \\
After 3 months & $0-12 \quad 3.16$ & 4.43 \\
& \multicolumn{2}{c}{ P value $<0.0001$} & \\
\hline
\end{tabular}


Table 7. Comparison between prophylactic effect of pumpkin seed oil, lactic acid mouth wash, zinc sulfate mouth wash and Nigella sativa oil.

\begin{tabular}{|c|c|c|c|c|c|c|c|c|}
\hline $\begin{array}{l}\text { OCMI } \\
\text { Score }\end{array}$ & $\begin{array}{c}\text { Pumpkin } \\
\text { seed oil }\end{array}$ & $\begin{array}{c}\text { Reduction in } \\
\text { mean }\end{array}$ & $\begin{array}{c}\text { Lactic } \\
\text { acid } \\
\text { MW }\end{array}$ & $\begin{array}{c}\text { Reduction in } \\
\text { mean }\end{array}$ & $\begin{array}{c}\text { Zinc } \\
\text { sulfate } \\
\text { MW }\end{array}$ & $\begin{array}{c}\text { Reduction in } \\
\text { mean }\end{array}$ & $\begin{array}{l}\text { Nigella } \\
\text { sativa oil }\end{array}$ & $\begin{array}{c}\text { Reduction in } \\
\text { mean }\end{array}$ \\
\hline At day 0 & 12.96 & & 17.50 & & 15.45 & & 13.65 & \\
\hline $\begin{array}{l}\text { At 1st } \\
\text { month }\end{array}$ & 1.24 & 11.72 & 6.40 & 11.1 & 9.45 & 6 & 10.95 & 2.7 \\
\hline $\begin{array}{l}\text { At 2nd } \\
\text { month }\end{array}$ & 1.12 & 11.84 & 4.90 & 12.6 & 3.15 & 12.3 & 4.90 & 8.75 \\
\hline $\begin{array}{l}\text { At 3rd } \\
\text { month }\end{array}$ & 0.84 & 12.12 & 4.10 & 13.4 & 4.00 & 11.45 & 7.35 & 6.3 \\
\hline
\end{tabular}

remained statistically significant throughout the course of therapy at the end of third month, with response rate $79.30 \%$ after 4 days of therapy and $94.38 \%$ after 8 days of therapy.

After stopping therapy, the effectiveness of pumpkin seed oil continued and remained statistically significant $(\mathrm{p}<0.0001)$ at the end of third month after stopping therapy, hence, pumpkin seed oil 100\% had a remission act in addition to its therapeutic and prophylactic effect in RAS.

No local or systemic side effects were noticed because pumpkin seed oil is edible oil.

The mechanism of action pumpkin seed oil in treatment of RAS cannot be clearly explained, but probable mechanisms of action of pumpkin seed oil may be through its anti-inflammatory [45] and antioxidant actions [42] [44].

When pumpkin seed oil was compared with other studies pumpkin seed oil appeared to be more effective than lactic acid 5\% mouth wash which showed response rate of $90.8 \%$ in one study, [28] and $69.16 \%$ in another study [49].

Also, this oil showed an effectiveness much better than $5 \%$ zinc sulfate mouth wash with response rate of $66.33 \%$, and $100 \%$ topical Nigella sativa oil with response rate of $60.60 \%$ [27].

The prophylactic effect of pumpkin seed oil are comparable to $5 \%$ lactic acid mouth wash and 5\% zinc sulphate mouth wash, and more effective than 100\% Nigella sativa oil (Table 7).

\section{Conclusion}

The present work had shown that $100 \%$ pumpkin seed oil is a new effective therapeutic and prophylactic agent in management of RAS, in addition to inducing remission in patients with RAS in drug free time, with no local or systemic side effects.

\section{Limitation of Study}

Further numbers of patients are needed.

\section{References}

[1] Jurge, S., Kuffer, R., Scully, C. and Porter, S.R. (2006) Recurrent Aphthous Stomati- 
tis. Oral Diseases, 12, 1-21. https://doi.org/10.1111/j.1601-0825.2005.01143.x

[2] Scully, C., Gorsky, M. and Lozada-Nur, F. (2003) The Diagnosis and Management of Recurrent Aphthous Stomatitis: A Consensus Approach. Journal of the American Dental Association, 134, 200-207. https://doi.org/10.14219/jada.archive.2003.0134

[3] Riera Matute, G. and Riera Alonso, E. (2011) Recurrent Aphthous Stomatitis Rhumatology. Reumatología Clínica, 7, 323-328. https://doi.org/10.1016/j.reumae.2011.05.002

[4] Scully, C. and Porter, S. (2008) Oral Mucosal Disease: Recurrent Aphthous Stomatitis. British Journal of Oral and Maxillofacial Surgery, 46, 198-206. https://doi.org/10.1016/j.bjoms.2007.07.201

[5] Yilmaz, S. and Cimen, K.A. (2010) Familial Behçet's Disease. Rheumatology International, 30, 1107-1109. https://doi.org/10.1007/s00296-009-1036-y

[6] Albanidou-Farmaki, E., Deligiannidis, A., Markopoulos, A.K., Katsares, V., Farmakis, K. and Parapanissiou, E. (2008) HLA Haplotypes in Recurrent Aphthous Stomatitis: A Mode of Inheritance. International Journal of Immunogenetics, 35, 427-432. https://doi.org/10.1111/j.1744-313X.2008.00801.X

[7] Lewkowicz, N., Lewkowic, P., Kurnatowska, A., Banasik, M., Glowacka, E., Cedzynski, M., Swierzko, A., Lauk-puchala, B. and Tchorzewski, H. (2003) Innate Immune System Is Implicated in Recurrent Aphthous Ulcer Pathogenesis. Journal of Oral Pathology \& Medicine, 32, 475-481. https://doi.org/10.1034/j.1600-0714.2003.00181.x

[8] Bachtior, E.W., Cornain, S., Siregor, B. and Rohorjo, T.W. (1999) Decreased $\mathrm{CD}^{+4} / \mathrm{CD}^{+8}$ Ratio in Major Type of Recurrent Aphthous Stomatitis Comparing Major to Minor Types of Ulcers. Asian Pacific Journal of Allergy and Immunology, 16, 75-79. https://doi.org/10.1111/j.1600-0714.1999.tb01986.x

[9] Healy, C.M. and Thornhill, M.H. (1999) Induction of Adhesion Molecule Expression on Blood Vessels and Keratinocytes in Recurrent Oral Ulceration. Journal of Oral Pathology \& Medicine, 28, 5-11.

[10] Eguia-del Valle, A., Martinez-Conde-Llamosas, R., Lopez-Vicente, J., Uribarri-Etxebarria, A. and Aguirre-Urizar, J.M. (2011) Salivary Levels of Tumor Necrotic Factor-Alpha in Patients with Recurrent Aphthous Stomatitis. Medicina Oral, Patologia Oral Y Cirugia Bucal, 16, 33-36. https://doi.org/10.4317/medoral.16.e33

[11] Borra, R.C., de Mesquita Barros, F., de Andrade Lotufo, M., Villanova, F.E. and Andrade, P.M. (2009) Toll-Like Receptor Activity in Recurrent Aphthous Ulceration. Journal of Oral Pathology \& Medicine, 38, 289-298. https://doi.org/10.1111/j.1600-0714.2008.00743.x

[12] HayrinenImmonen, R. (1992) Immnue-Activation in Recurrent Oral Ulcers. Scandinavian Journal of Dental Research, 100, 222-227.

[13] Brozovic, S., Vucicevic-Boras, V., Mrovak-Stipetic, M. and Jukic, S. (2002) Salivary Levels of Vascular Endothelial Growth Factor (VEGF) in Recurrent Aphthous U1ceration. Journal of Oral Pathology \& Medicine, 31, 106-108. https://doi.org/10.1034/j.1600-0714.2002.310208.x

[14] Natah, S.S., Konttinen, Y.T., Enattah, N.S., Ashammakhi, N., Sharkey, K.A. and Häyrinen-Immonen, R. (2004) Recurrent Aphthous Ulcers Today: A Review of Growing Knowledge. International Journal of Oral \& Maxillofacial Surgery, 33, 221-234. https://doi.org/10.1006/ijom.2002.0446

[15] Darniroglu, H. and Dundar, S. (1997) Behcet's Disease and Chronic Neutropenia. Scandinavian Journal of Rheumatology, 26, 130-132. 
https://doi.org/10.3109/03009749709115832

[16] Victoria, J.M., Kalapothakis, E., de Silva, J.F. and Gomez, R.S. (2003) Helicobacter Pylori DNA in Recurrent Aphthous Stomatitis. Journal of Oral Pathology \& Medicine, 32, 219-223. https://doi.org/10.1034/j.1600-0714.2003.00136.x

[17] Tas, D.A., Yakar, T., Sakalli, H. and Serin, E. (2013) Impact of Helicobacter Pylori on the Clinical Course of Recurrent Aphthous Stomatitis. Journal of Oral Pathology \& Medicine, 42, 89-94. https://doi.org/10.1111/j.1600-0714.2012.01197.x

[18] Ghodratnama, F., Wray, D. and Bagg, J. (1999) Detection of Serum Antibodies against Cytomegalovirus, Varicella Zoster Virus and Human Herpesvirus 6 in $\mathrm{Pa}$ tients with Recurrent Aphthous Stomatitis. Journal of Oral Pathology \& Medicine, 28, 12-15. https://doi.org/10.1111/j.1600-0714.1999.tb01987.x

[19] Crispian, S. (2004) Aphthous Ulcers. Medicine Specialties Otolaryngology and Facial Plastic Surgery. 11.

[20] McCurtan, B.E. and Sullivan, A. (1992) The Association of Menstrual Cycle, Pregnancy and Menopause with Recurrent Oral Aphthous Stomatitis: A Review and Critique. Obstetrics \& Gynecology, 80, 455-458.

[21] Tuzun, B., Wolf, R., Tuzun, Y. and Serdaroglu, S. (2000) Recurrent Aphthous Stomatitis and Smoking. International Journal of Dermatology, 39, 358-360. https://doi.org/10.1046/j.1365-4362.2000.00963.x

[22] Floto, R.A. and Smith, K.G. (2003) The Vagus Nerve, Macrophages and Nicotine. The Lancet, 361, 1069-1070. https://doi.org/10.1016/S0140-6736(03)12902-9

[23] Scheid, P., Bohadana, A. and Martinet, Y. (2000) Nicotine Patches for Aphthous Ulcers Due to Behcet's Syndrome. The New England Journal of Medicine, 343, 1816. https://doi.org/10.1056/NEJM200012143432418

[24] Gallo Cde, B., Mimura, M.A. and Sugaya, N.N. (2009) Pschological Stress and Recurrent Aphthous Stomatitis. Clinics (Sao Paulo), 64, 645-648.

[25] Sharquie, K.E. and Najim, R.A. (2001) Honey as a New Skin Tissue Preservative. Journal of Pan-Arab League of Dermatologists, 12, 49-54.

[26] Sharquie, K.E., Al-Tammimy, S.M., Al-Mashhadani, S., Hayani, R.K. and Al-Nuaimy, A.A. (2006) Lactic Acid 5 Percent Mouthwash Is an Effective Mode of Therapy in Treatment of Recurrent Aphthous Ulcerations. Dermatology Online Journal, 12, 2.

[27] Sharquie, K.E., AL-mashhaddani, Al-Nuaimy, A.A. and Shubber, S.A. (2006) The Therapeutic and Prophylactic Efficacy of 5\% Lactic Acid, 5\% Zinc Sulphate Mouth Wash and Topical 100\% Nigella sativa Oil in Management of Recurrent Aphthous Ulcers.

[28] Baccaglini, L., Lalla, R.V., Bruce, A.J., Sartori-Valinotti, J.C., Latortue, M.C. and Carrozzo, M. (2011) Urban Legends: Recurrent Aphthous Stomatitis. Oral Diseases, 17, 755-770. https://doi.org/10.1111/j.1601-0825.2011.01840.x

[29] Sharquie, K.E. and Hayani, R.K. (2004) BCG as a New Therapeutic and Prophylactic Agent in Patients with Sever Oral Aphthosis. Clinical and Experimental Rheumatology, 22, 120.

[30] Sharquie, K.E., Najim, R.A., Al-Hayani, R.K., Al-Nuaimy, A.A. and Maroof, D.M. (2008) The Therapeutic and Prophylactic Role of Oral Zinc Sulfate in Management of Recurrent Aphthous Stomatitis (Ras) in Comparison with Dapsone. Saudi Medical Journal, 29, 734-738.

[31] De Abreu, M.A., Hirata, C.H., Pimentel, D.R. and Weckx, L.L. (2009) Treatment of 
Recurrent Aphthous Stomatitis with Clofazimine. Oral Surgery, Oral Medicine, Oral Pathology, Oral Radiology, and Endodontology, 108, 714-721. https://doi.org/10.1016/j.tripleo.2009.05.009

[32] Femiano, F., Buonaiuto, C., Gombos, F., Lanza, A. and Cirillo, N. (2010) Pilot Study on Recurrent Aphthous Stomatitis (RAS): A Randomized Placebo-Controlled Trial for the Comparative Therapeutic Effects of Systemic Prednisone and Systemic Montelukast in Subjects Unresponsive to Topical Therapy. Oral Surgery, Oral Medicine, Oral Pathology, Oral Radiology, and Endodontology, 109, 402-407. https://doi.org/10.1016/j.tripleo.2009.10.024

[33] Pakfetrat, A., Mansourian, A., Momen-Heravi, F., et al. (2010) Comparison of Colchicine versus Prednisolone in Recurrent Aphthous Stomatitis: A Double-Blind Randomized Clinical Trial. Clinical \& Investigative Medicine, 33, 189-195. https://doi.org/10.25011/cim.v33i3.13725

[34] Sharquie, K.E., Najim, R.A. and Abu-Raghif, A.R. (2002) Dapsone in Behçet's Disease: A Double-Blind, Placebo-Controlled, Cross-Over Study. The Journal of Dermatology, 29, 267-279. https://doi.org/10.1111/j.1346-8138.2002.tb00263.x

[35] Fontes, V., Machet, L., Huttenberger, B., Lorette, G. and Vaillant, L. (2002) Recurrent Aphthous Stomatitis: Treatment with Colchicine. An Open Trial of 54 Cases. Annales de Dermatologie et de Vénéréologie, 129, 1365-1369.

[36] Sharquie, K.E., Helmi, R.M., Noiami, A.A., Al-Hayani, R.K. and Kadhom, M.A. (2015) Therapeutic Role of Isotretinoin in the Management of Recurrent Aphthous Stomatitis (Single-Blind Controlled Therapeutic Study). Journal of Cosmetics, Dermatological Sciences and Applications, 5, 15-21. https://doi.org/10.4236/jcdsa.2015.51003

[37] Nwokolo, E. and Sim, J.S. (1987) Nutritional Assessment of Defatted Oil Meals of Melon (Colocynthiscitrullus L.) and Fluted Pumpkin (Telfariaoccidentalis Hook) by Chick Assay. Journal of Science and Food Agriculture, 38, 237-246. https://doi.org/10.1002/jsfa.2740380307

[38] Stevenson, D.G., Eller, F.J., Wang, L., Jane, J.L., Wang, T. and Inglett, G.E. (2007) Oil and Tocopherol Content and Composition of Pumpkin Seed Oil in 12 Cultivars. Journal of Agricultural and Food Chemistry, 55, 4005-4013. https://doi.org/10.1021/jf0706979

[39] Murković, M.V., Piironen, A.M., Lampi, T.K. and Sontag, G. (2004) Changes in Chemical Composition of Pumpkin Seeds during Roasting Process for Production of Pumpkin Seed Oil. Food Chemistry, 84, 359-365. https://doi.org/10.1016/S0308-8146(03)00240-1

[40] Szterk, A., Roszko, M., Sosińska, E., Derewiaka, D. and Lewicki, P. (2010) Chemical Composition and Oxidative Stability of Selected Plant Oils. Journal of American Oil Chemist's Society, 87, 637-645. https://doi.org/10.1007/s11746-009-1539-4

[41] Sotelo, A., López-García, S. and Basurto-Peña, F. (2007) Content of Nutrient and Antinutrient in Edible Flowers of Wild Plants in Mexico. Plant Foods for Human Nutrition, 62, 133-138. https://doi.org/10.1007/s11130-007-0053-9

[42] Imaeda, N., Tokudome, Y., Ikeda, M., et al. (1999) Foods Contributing to Absolute Intake and Variance in Intake of Selected Vitamins, Minerals and Dietary Fiber in Middle-Aged Japanese. Journal of Nutritional Science and Vitaminology, 45, 519-532. https://doi.org/10.3177/jnsv.45.519

[43] Dang, C. (2004) Effect of Pumpkin Distillable Subject on Lipid Peroxidation and the Activity of Antioxidative Enzyme Induced by Plumbum in Mouse. Chinese Journal of Clinical Rehabilitation, 8, 4378-4379. (In Chinese) 
[44] Xu, G.H. (2000) A Study of the Possible Antitumour Effect and Immunompetence of Pumpkin Polysaccharide. J Wuhan Prof Med Coll., 28, 1-4.

[45] De Oliveira, M.L.M., Nunes-Pinheiro, D.C.S., Bezerra, B.M.O., Leite, L.O., Tomé, A.R. and Girão, V.C.C. (2013) Topical Anti-Inflammatory Potential of Pumpkin (Cucurbitapepo L.) Seed Oil on Acute and Chronic Skin Inflammation in Mice. Acta Scientiae Veterinariae, 41, 1168.

[46] Hammer, K.A., Carson, C.F. and Riley, T.V. (1999) Antimicrobial Activity of Essential Oils and Other Plant Extracts. Journal of Applied Microbiology, 86, 985-990. https://doi.org/10.1046/j.1365-2672.1999.00780.x

[47] MacGibbon, D.B. and Mann, J.D. (1986) Inhibition of Animal and Pathogenic Fungal Proteases by Phloem Exudate from Pumpkin Fruits (Cucurbitaceae). Journal of the Science of Food and Agriculture, 37, 515-522.

https://doi.org/10.1002/jsfa.2740370602

[48] Huang, X.E., Hirose, K., Wakai, K., et al. (2004) Comparison of Lifestyle Risk Factors by Family History for Gastric, Breast, Lung and Colorectal Cancer. Asian Pacific Journal of Cancer Prevention, 5, 419-427.

[49] Sharquie, K.E., AL-mashhaddani, Al-Nuaimy, A.A., Hayani, R.K. and Shubber, S.A. (2012) Lactic Acid 5\% Mouthwash Is an Effective Therapeutic and Prophylactic Agent in Treatment of Recurrent Aphthous Ulcer. The Iraq Postgradute Medical Journal, 11, 3 . 